\title{
Respuesta al artículo: La concentración de tratamientos puede mejorar los resultados en cirugía compleja del cáncer
}

\section{Response to the article: Concentration of treatments can improve clinical results in complex cancer surgery}

\section{Sr. Editor:}

Hemos leído con gran interés la editorial de Borras y Guarga ${ }^{1}$ que creemos expresa el pensamiento de muchos cirujanos de nuestro país ${ }^{2}$ y con la que coincidimos, al mismo tiempo que quisiéramos hacer una serie de reflexiones constructivas sobre algunos aspectos que no vemos reflejados del todo en la misma.

El que la concentración en determinados procedimientos disminuya la mortalidad ${ }^{1-3}$, ya es una buena razón por sí misma para plantearse la centralización, a pesar de que no todos los estudios lo demuestran ${ }^{4}$, pero no nos parece suficiente el solo hecho de que el volumen por sí mismo sea el principal criterio que defina el centro de referencia, ya que se pueden operar muchos casos, a nivel individual o de servicio, pero si los resultados no se auditan, se comparan o se hacen públicos, podemos caer en el error de que cantidad no sea igual a calidad ${ }^{3}$.

Desde la Sección de Formación de la Asociación Española de Cirujanos http://www.aecirujanos.es pensamos que las unidades de un servicio que pretenda centralizar procedimientos deberían de estar certificadas al igual que sus profesionales, al mismo tiempo que disponer de tecnología puntera e innovadora que ofrezca las mejores oportunidades de tratamiento a nuestros pacientes, y esto sí que sería un requisito básico para que la centralización tuviese un sentido real, además del volumen, porque significa que los resultados de los profesionales y del centro, están auditados y se pueden comparar. Si tenemos en cuenta que la inmensa mayoría de estos pacientes van a ser tratados en algún momento de su proceso por un cirujano, y en una coyuntura en la que está claro que debemos de apostar por la centralización de procedimientos, sería importante y oportuno, que desde las distintas secciones de la AEC se estableciesen los estándares de calidad que una unidad de referencia debería de reunir para centralizar procedimientos, y que junto al esfuerzo que se está haciendo desde la Unión Europea de Médicos Especialistas https://www.uemssurg.org/ con los Board, estos tuviesen de verdad un sentido real y práctico y se solapasen con las propuestas necesarias de definir las áreas de capacitación específica y sus diplomas ${ }^{5}$ que contemplaba el paralizado proyecto de troncalidad, y que ya intuía la Ley de Ordenación de las Profesiones Sanitarias, que sí que está vigente, por lo que nuestra sociedad debería tener un liderazgo claro y visible, y no solo en la cirugía oncológica.

\section{Agradecimientos}

A todos los miembros de la Junta de la Sección de Formación Postgraduada de la Asociación Española de Cirujanos.

\section{B I B L I O G R A F Í A}

1. Borras JM, Guarga A. La concentración de tratamientos puede mejorar los resultados en cirugía compleja del cáncer. Cir Esp. 2018;96:315-6.

2. Codina-Cazador A, Biondo S. El terciarismo en el cáncer de recto. Cir Esp. 2015;93:273-5.

3. Finks JF, Osborne NH, Birkmeyer JD. Trends in Hospital Volume and Operative. Mortality for High-Risk Surgery. N Engl J Med. 2011;364:2128-37.

4. Bos AC, van Erning FN, Elferink MA, Rutten HJ, van Oijen MG, de Wilt JH, et al. No difference in overall survival between

Véase contenido relacionado en DOI: https://doi.org/10.1016/j.ciresp.2017.09.013 
hospital volumes for patients with colorectal cancer in the Netherlands. Dis Colon Rectum. 2016;59:943-52.

5. Miguelena Bobadilla JM, Morales-García D, Iturburu Belmonte I, Alcázar Montero JA, Sera Aracil X, Docobo Durántez F, et al. Formación en Cirugía General en España: Troncalidad y áreas de capacitación específica. Cir Esp. 2015;93:147-51.

Dieter Morales-García ${ }^{a, b, *}$, Jose Antonio Alcazar-Montero ${ }^{\mathrm{b}, \mathrm{c}}$, Jose María Miguelena-Bobadilla ${ }^{b, d}$ y Xavier Serra Aracil ${ }^{b, e}$

${ }^{a}$ Servicio de Cirugía General y del Aparato Digestivo, Hospital Universitario Marqués de Valdecilla, Santander, Cantabria, España ${ }^{\mathrm{b}}$ Sección de Formación Postgraduada, Asociación Española de Cirujanos (AEC)
'Servicio de Cirugía General y del Aparato Digestivo, Hospital Universitario de Salamanca, Salamanca, España

dServicio de Cirugía General y del Aparato Digestivo, Hospital Universitario Miguel Servet, Zaragoza, España

'Servicio de Cirugía General y del Aparato Digestivo, Complejo Hospitalario Parc Taulí, Sabadell, Barcelona, España

*Autor para correspondencia.

Correo electrónico: dms11@me.com (D. Morales-García).

https://doi.org/10.1016/j.ciresp.2018.08.012 0009-739X/

(C) 2018 AEC. Publicado por Elsevier España, S.L.U. Todos los derechos reservados. 